\title{
Impact of mechanically pre-treated anaerobic digestates on soil properties
}

\author{
A. Voelkner ${ }^{*}$, S. Ohl², D. Holthusen ${ }^{1}$, E. Hartung 2 , J. Dörner ${ }^{3}$, and R. Horn ${ }^{1}$ \\ ${ }^{1}$ Institute of Plant Nutrition and Soil Science, University of Kiel, Hermann-Rodewald-Str. 2, \\ 24118 Kiel, Germany. 'Institute of Agricultural Engineering, University of Kiel, Olshausenstr. 40, \\ 24098 Kiel, Germany. ${ }^{3}$ Instituto de Ingeniería Agraria y Suelos, Facultad de Ciencias Agrarias, \\ Universidad Austral de Chile, Valdivia, Chile. ${ }^{*}$ Corresponding author: a.voelkner@soils.uni-kiel.de
}

\begin{abstract}
The production of biogas by anaerobic digestion results in the production of digestates, which are intended to be used as organic fertilizer in agriculture. However, these anaerobic digestates (AD) - besides having benefits for the nutrient status of soils - are assumed to have adverse consequences for soil properties. It is thus the objective of this study to determine the effects of $30 \mathrm{~m}^{3} \mathrm{ha}^{-1}$ of $\mathrm{AD}^{\prime} \mathrm{s}$ on $\mathrm{pH}$, electrical conductivity (EC), and the wetting behavior determined by the Repellency Index (RI) and the contact angle (CA) of a loamy Cambic Luvisol and a sandy Podzol. The AD's, derived from mechanically pre-treated (grinding/chopping) input substrates (IS) from maize (Zea mays L.) and sugar beet (Beta vulgaris L.) in variable shares (100\%, $80 \% / 20 \%)$, were mixed with homogenized (sieved to $\leq 2 \mathrm{~mm}$ ) soils by stirring. Blending of the AD increased the EC significantly and induced more alkaline conditions; the extent of this change was highly dependent on soil texture. The use of $\mathrm{AD}$ derived from ground IS resulted in more hydrophobic conditions compared to AD from chopped IS. This leads in the current study to the conclusion that the mechanical pre-treatment of the IS for anaerobic digestion and also the soil texture are decisive factors controlling both the physicochemical and the hydraulic effects of digestates to the soils.
\end{abstract}

Keywords: Anaerobic digestates, soil properties, water repellency, electrical conductivity

\section{Introduction}

The worldwide debate on climate change and technological approaches to mitigate the negative consequences of it has intensified over the last years. Amongst others, Alburquerque et al. (2012) stated that the effects of global warming can be reduced by the replacement of fossil fuels with renewable and environmentally compatible energy sources by establishing anaerobic fermentation processes. The technology is based on the reduction of biodegradable organic residues from energy rich grain crops, maize silage, or animal manure under exclusion of oxygen in a four-step 
process (hydrolysis, acidogenesis, acetogenesis, and methanogenesis) (Ariunbaatar et al., 2014). The biogas generated produces a digestate as a by-product, which is used as organic fertilizer for agriculture due to high nutrient contents, like mineral nitrogen, plant available ammonia, and phosphorus (Sørensen and Møller, 2009). The application of digestates can stimulate microbial activity and improve soil fertility through the supply of organic matter (Réveillé et al., 2003, Curaqueo et al., 2014). But the organic matter of digestates contains humic-like acids and fatty acids as well as recalcitrant and amphiphilic substances consisting of hydrophilic and hydrophobic groups, which can attach to soil particles and reduce their wettability (Arye et al., 2011, Antilen et al., 2014). With the digestates, soluble monovalent salts (mainly sodium and potassium) are applied to the soil, possibly resulting in dispersion of soil particles. Furthermore, organic acids are transferred to the soil matrix and may cause the acidification of soils (Tejada and González, 2007). Both processes can weaken a stable soil structure. Thus, if not adequately managed, the digestates can be a serious risk for soil, groundwater, and the environment (Sciubba et al., 2012). Whether digestates serve as a beneficial organic amendment or as risk for agricultural land is determined by the composition of organic compounds (recalcitrant and labile organic fractions) and the accessibility of particle surfaces, and thus their microbial degradability (Magdoff and Weil, 2004). Before beginning of the anaerobic digestion process, mechanical pre-treatment of the used input substrates (IS), which is a proven and widespread method, is aimed to enhance the accessibility of the substrate particles for microbial decay and to improve the digestion process (Lindmark et al., 2012). The facilitated contact between microorganisms and IS particles leads furthermore to an accelerated degradation of the organic compounds (Wang et al., 2014) during the fermentation process, which may also have an impact on the quality and composition of the digestates and, hence, influences the effects of digestates on soil properties.

Apart from principle considerations, it is, however, unknown how digestates derived from mechanically reduced particle size of IS may affect physicochemical soil properties and may also result in a possible hydrophobization. For this reason the objectives of this study were to explore the effect of digestate application derived from differently pre-treated IS on physicochemical soil properties and the wettability, with special consideration given to the particle size of the IS used for digestion and to the soil texture. It was hypothesized that the excessive size reduction of the IS by grinding for digestate production has a more pronounced effect on soils compared to the digestates derived from chopped IS due to the enlargement of the specific surface area of the IS particles.

\section{Materials and Methods}

\subsection{Study sites and soil characteristics}

For the laboratory measurements, soil samples from two arable land sites with different textures were taken in June 2013 from the upper layer $(0-10 \mathrm{~cm})$ of the A-horizon of the following two arable soils at the research farms of the University Kiel, Germany:

(1) A Cambic Luvisol derived from Weichselian glacial till from Hohenschulen (HS), characterized as sandy loam (S14) (FAO, 1998) and covered with grass;

(2) A Podzol derived from glacial outwash from Karkendamm (KD), classified as sandy sand ( $\mathrm{Ss}$ ) (FAO, 1998) and sown with oats (Avena sativa L.). The disturbed soil material was air-dried after sampling, homogenized, and sieved to $\leq 2 \mathrm{~mm}$. The 
chemical analysis of the samples was conducted according to standard procedures.

\subsection{Properties of digestates}

Soil chemical and physical analyses were conducted after applying liquid digestates from batch-fermentation (generated at the Institute of Agricultural Engineering, University of Kiel). The inoculum (substrate rich in microorganisms for the anaerobic digestion process) was derived from the biogas plant in Bülk, Germany. To compare the effect of mechanically pre-treated input substrate (IS) on the digestate quality, on the one hand fresh input substrate (IS) from maize and sugar beet silage was air-dried $\left(58^{\circ} \mathrm{C}\right)$ and ground before starting the fermentation process. On the other hand, ensiled IS from these energy crops were chopped befor anaerobic digestion. Twenty to $30 \mathrm{~g}$ of the IS was added to the inoculum and the mixture was digested for 28 days at $38^{\circ} \mathrm{C}$. The digestates were produced with 9 repetitions for each IS. Measurements were conducted from a composite sample of these 9 repetitions $(n=1)$.

The chemical characteristics of the digestates were analyzed at the LUFA GmbH, Kiel, and the electrical conductivity and $\mathrm{pH}$ from the digestates were measured at the Institute for Plant Nutrition and Soil Science, University of Kiel.

The digestates contained the following ratios of maize and sugar beet:

(1) $100 \%$ ground maize (gr-M100)

(2) $100 \%$ chopped maize (ch-M100)

(3) $100 \%$ ground sugar beet (gr-SB100)

(4) $100 \%$ chopped sugar beet (ch-SB100)

(5) $80 \%$ ground sugar beet and $20 \%$ maize (grSB80M20)

(6) $80 \%$ chopped sugar beet and $20 \%$ maize (chSB80M20)
(7) $80 \%$ ground maize and $20 \%$ sugar beet (grM80SB20)

(8) $80 \%$ chopped maize and $20 \%$ sugar beet (chM80SB20)

(9) an untreated control (C) which was treated with demineralized water.

\subsection{Sample preparation and soil measurements}

To analyse the impact of anaerobic digestates on soil chemical and physical properties, a laboratory study was implemented using homogenized $(\leq 2 \mathrm{~mm})$ soil. For the measurements of $\mathrm{pH}$, electrical conductivity, and contact angle, $480 \mathrm{~g}$ of soil was accurately mixed with $30 \mathrm{ml}$ of each digestate by stirring, which is equivalent to the usual application amounts of $30 \mathrm{~m}^{3}$ $\mathrm{ha}^{-1}$. Additionally, a control treatment (C) was prepared using the equivalent amount of demineralized water. There were two soil-digestate-mixtures for each treatment and study site. During the exposure time of 10 days for soil and digestates/demineralized water to reach a microbial equilibrium, the mixtures were stored at $10{ }^{\circ} \mathrm{C}$. Afterwards, the mixtures were again air-dried, re-homogenized, and sieved to $\leq 2$ $\mathrm{mm}$ diameter. From each mixture two subsamples for determining $\mathrm{pH}$ and electrical conductivity and six subsamples for investigation of the contact angle were taken. To measure the intrinsic sorptivity of water and ethanol into the soil, the remaining soil from the mixtures was compacted into 6 soil columns (repetitions) for each treatment and study site with a volume of $93 \mathrm{~cm}^{3}$ and a bulk density of $1.45 \mathrm{~g} \mathrm{~cm}^{-3}$. Air-dried soil material from mixtures $(\leq 2 \mathrm{~mm})$ was analysed for electrical conductivity (EC) in a 1:5 (soil:water) suspension and $\mathrm{pH}$ in a 1:2.5 (soil: $\left.\mathrm{CaCl}_{2}\right)$ suspension in four replicates according to Schlichting et al. (1995).

To assess soil water repellency, the contact angle (CA) of air-dried soil material $(\leq 2 \mathrm{~mm})$ (Bachmann et al., 
2006) and the sorptivity-based Repellency Index (RI) of moist soil samples (Tillman et al., 1989) were detected. The wettability of air-dried soil samples was determined measuring the advancing and receding CA with the Wilhelmy-Plate-Method (WPM) in a precision tensiometer (KRÜSS, Germany). A thin glass plate covered with a one-grain layer of soil particles was attached to an electronic balance and was then immersed into distilled water with a known surface tension, and the force $\mathrm{F}[\mathrm{N}]$ acting on the plate was measured (Bachmann et al., 2006). The advancing $\mathrm{CA}(\theta)\left[^{\circ}\right]$ can be calculated by the equation:

$$
\cos \theta=F /\left(\rho \sigma_{L V}\right)
$$

where $\sigma_{\mathbb{V}}\left[\mathrm{mN} \mathrm{m}^{-1}\right]$ denotes the surface tension and $\rho$ describes the liquid density $\left[\mathrm{g} \mathrm{cm}^{-3}\right]$. With the WPM it is possible to measure CA from $0^{\circ}$ to $180^{\circ}$. The advancing contact angle above $90^{\circ}$ indicates hydrophobic conditions. The measurements were performed with six replications.

The wettability of the moist soil was determined by measuring the sorptivity of water (non-wetting) and ethanol as a reference liquid (wetting, $\mathrm{CA}=0^{\circ}$ ) using a microinfiltrometer according to Hallett and Young (1999). The sorptivity S was calculated using an equation:

$$
S=\sqrt{\frac{Q f}{4 b r}}
$$

where $Q$ represents the rate of liquid adsorption of the soil which was recorded from the mass loss of the liquid from the reservoir placed on a balance at intervals of 15 seconds, $f$ is the air-filled porosity, $b$ is a parameter dependent on the soil-water diffusivity function (0.55) and $r$ is the radius of the infiltrometer tip $(1.4 \mathrm{~mm})$.
The RI was calculated from the relationship of the intrinsic sorptivity of water $\mathrm{S}_{\text {water }}$ and ethanol $\mathrm{S}_{\text {ethanol }}$ to characterize the infiltration capacity of a soil as a function of time and air-filled pore space:

$$
R=1.95\left(\frac{S_{\text {Ethanol }}}{S_{\text {Water }}}\right)
$$

The constant 1.95 represents the different values of surface tension and viscosity of water and ethanol.

The RI represents to what extent the infiltration of a liquid into the soil is reduced by water repellency (Hallett et al., 1999). A RI $=1$ indicates non-repellent conditions, and a $\mathrm{RI} \geq 1.95$ characterizes water repellency (Tillman et al., 1989).

\subsection{Statistical analysis}

For statistical evaluations the statistical software $\mathrm{R}$ (version 2.15.3) was applied. A graphical residual analysis (Shapiro-Wilk-Test) was done to verify the normal distribution of the values. The statistical mixed model involves the various digestates, experimental fields, and the pre-treatment of the input substrates. Tukey`s least significant difference test was used to test for statistical significance of differences between the individual means with a confidence interval of $p$ $\leq 0.05$.

\section{Results}

\subsection{Physicochemical properties}

Both soils exhibited slightly acid conditions. The HS soil showed more alkaline characteristics compared to the KD soil as well as a difference in organic matter (Table 1). 
Table 1. Average values $(\mathrm{n}=2)$ of basic properties of the A-horizons $(0-10 \mathrm{~cm})$ of a loamy Cambic Luvisol (HS) and a sandy Podzol (KD).

\begin{tabular}{|c|c|c|c|}
\hline & & \multicolumn{2}{|l|}{ Experimental sites } \\
\hline & & Hohenschulen (HS) & Karkendamm (KD) \\
\hline \multicolumn{2}{|c|}{$\mathrm{pH}\left(0.02 \mathrm{~m} \mathrm{CaCO}_{3}\right)[-]$} & 6.6 & 5.6 \\
\hline \multicolumn{2}{|c|}{ Organic carbon [\%] } & 1.2 & 3.1 \\
\hline \multicolumn{2}{|c|}{ Total N [ $\left.\mathrm{mg} \mathrm{g}^{-1}\right]$} & 0.74 & 1.25 \\
\hline \multirow[t]{3}{*}{ Texture } & Clay [\%] & 16.6 & 2.6 \\
\hline & Silt $[\%]$ & 27.2 & 5.8 \\
\hline & Sand [\%] & 56.2 & 91.6 \\
\hline
\end{tabular}

Table 2. Chemical properties $(n=1)$ of the digestates used in this study. OS = original substance; $<=$ below the detection limit.

\begin{tabular}{|c|c|c|c|c|c|c|c|c|}
\hline & \multicolumn{2}{|l|}{ M100 } & \multicolumn{2}{|l|}{ SB100 } & \multicolumn{2}{|c|}{ SB80M20 } & \multicolumn{2}{|c|}{ M80SB20 } \\
\hline & gr- & ch- & gr- & ch- & gr- & ch- & gr- & ch- \\
\hline $\mathrm{EC}\left[\mu \mathrm{S} \mathrm{cm}^{-1}\right]$ & 81 & 83 & 84 & 82 & 91 & 85 & 90 & 87 \\
\hline pH [-] & 8.25 & 7.93 & 8.21 & 7.85 & 7.74 & 7.82 & 7.75 & 7.85 \\
\hline Acetic acid $\left[\mathrm{g} \mathrm{kg}^{-1} \mathrm{OS}\right]$ & $<0.050$ & $<0.050$ & $<0.050$ & $<0.050$ & 0.083 & $<0.050$ & $<0.050$ & $<0.050$ \\
\hline $\begin{array}{l}\text { Acetic acid equivalents [mg } \\
\mathrm{ka}^{-1} \text { ] }\end{array}$ & 390 & 170 & 250 & 140 & 170 & 240 & 250 & 270 \\
\hline Dry solids [\% OS] & 2.8 & 3.0 & 2.6 & 2.8 & 2.8 & 2.9 & 2.8 & 3.2 \\
\hline $\mathrm{NH}_{4}-\mathrm{N}[\%$ OS] & 0.21 & 0.14 & 0.15 & 0.13 & 0.14 & 0.14 & 0.14 & 0.15 \\
\hline Total N [\% OS] & 0.24 & 0.24 & 0.26 & 0.23 & 0.17 & 0.26 & 0.18 & 0.25 \\
\hline $\mathrm{P}[\%$ OS $]$ & 0.23 & 0.27 & 0.22 & 0.25 & 0.28 & 0.23 & 0.29 & 0.24 \\
\hline $\mathrm{K}[\% \mathrm{OS}]$ & 0.03 & 0.04 & 0.03 & 0.03 & 0.05 & 0.03 & 0.04 & 0.04 \\
\hline $\mathrm{Mg}[\%$ OS $]$ & 0.02 & 0.03 & 0.02 & 0.03 & 0.04 & 0.02 & 0.04 & 0.02 \\
\hline $\mathrm{Ca}[\%$ OS] & 0.02 & 0.03 & 0.02 & 0.02 & 0.02 & 0.02 & 0.02 & 0.02 \\
\hline $\mathrm{Na}\left[\mathrm{mg} \mathrm{kg}^{-1} \mathrm{OS}\right]$ & 139 & 179 & 138 & 167 & 159 & 140 & 159 & 145 \\
\hline
\end{tabular}


Table 3. Soil EC and $\mathrm{pH}$ after the application of digestates to samples from Hohenschulen (HS) or Karkendamm $(\mathrm{KD})$. Values represent the mean $(\mathrm{n}=4)$ for each amendment.

\begin{tabular}{|c|c|c|c|c|c|c|c|c|c|}
\hline \multicolumn{3}{|c|}{ M100 } & \multicolumn{2}{|l|}{ SB100 } & \multicolumn{2}{|c|}{ SB80M20 } & \multicolumn{3}{|c|}{ M80SB20 } \\
\hline & gr- & ch- & gr- & ch- & gr- & ch- & gr- & ch- & C \\
\hline \multicolumn{10}{|c|}{ Electrical conductivity (EC) $\left[\mu \mathrm{S} \mathrm{cm}^{-1}\right]$} \\
\hline HS & $253 \pm 5.1$ & $206 \pm 0.5$ & $214 \pm 6.2$ & $205 \pm 4.1$ & $246 \pm 4.9$ & $227 \pm 5.7$ & $217 \pm 3.8$ & $222 \pm 5.0$ & $187 \pm 0.3$ \\
\hline KD & $111 \pm 1.9$ & $117 \pm 7.2$ & $110 \pm 1.5$ & $103 \pm 2.9$ & $121 \pm 5.9$ & $120 \pm 1.3$ & $119 \pm 3.3$ & $121 \pm 1.0$ & $68 \pm 1.2$ \\
\hline \multicolumn{10}{|c|}{$\mathrm{pH}[-]$} \\
\hline HS & $7.21 \pm 0$ & $7.24 \pm 0$ & $7.23 \pm 0$ & $7.28 \pm 0$ & $7.23 \pm 0$ & $7.16 \pm 0$ & $7.21 \pm 0$ & $7.16 \pm 0$ & $6.64 \pm 0$ \\
\hline KD & $5.74 \pm 0$ & $5.82 \pm 0$ & $5.65 \pm 0$ & $5.71 \pm 0$ & $5.76 \pm 0$ & $5.83 \pm 0$ & $5.81 \pm 0.1$ & $5.89 \pm 0.1$ & $5.19 \pm 0$ \\
\hline
\end{tabular}

The digestates exhibited an alkaline character (Table 2); however the digestates from monofermentation derived from ground IS exceeded a $\mathrm{pH}$ of 8 . The digestate grSB80M20 contained more acetic acids compared to the other digestates and the amendment gr-M100 showed the highest ammonium content. Other fermentation acids (e.g., propionic acid and butyric acid) could not be proven. The digestates from monofermentation contained more sodium ions when made from chopped IS, but the digestates from cofermentation had more sodium when derived from ground IS (Table 2).

The control (C) of the HS soil showed a threefold higher EC compared to the control (C) of the KD soil (Table 3). The electrical conductivity of both the loamy and the sandy soil was significantly increased by the digestate amendment. The extent of increase was affected by the type of mechanical pre-treatment of the IS used for digestion. The EC of the HS soil increased more sharply after application of digestates from ground IS than after the supply of digestates from chopped IS. To the contrary, the EC of the KD soil exhibited higher levels after the amendment with digestates derived from chopped IS compared to the input of digestates from ground IS (Table 3).

The control (C) of both soils was characterized by slightly acidic conditions. The interference with digestates induced a significant $(p<0.05)$ shift to more alkaline conditions compared to the control (Table 3). The blending of digestates derived from chopped IS (M100 and SB100) into the HS soil resulted in more alkaline conditions compared to the mixture of the soil with digestates from ground IS. In-between the various substrates various reactions could be determined (see treatments SB80M20 and M80SB20, which showed a higher $\mathrm{pH}$ after use of ground IS while after application of chopped IS the $\mathrm{pH}$ of the $\mathrm{KD}$ soil was higher than after addition of ground IS).

\subsection{Wetting properties}

When compared to the control (C) of the HS soil, the Repellency Index (RI) increased after the application of digestates which was not significant (Figure 1). Just the amendment ch-M100 exhibited a slight decrease of RI 
compared to the control. The RI of most amendments did not achieve the hydrophobic area $(R I \geq 1.95)$ with exception of the variant gr-M100. In general, the digestates derived from ground IS induced a higher RI compared to the digestates from chopped IS (with exception of the variant gr-M80SB20 and ch-M80SB20). This difference was significant $(p<0.05)$ for the amendment M100.

The RI $>1.95$ of the control (C) of the KD soil exhibited resistance to wetting (Figure 2). After digestate application, the RI just partly exceeded the value of the control. The digestates derived from chopped IS in cofermentation (R80M20 and M80R20) fell below the control and remained clearly in the hydrophilic range. Without exception, the application of digestates from ground IS resulted in higher RI compared to the digestates from chopped IS; however, the difference between the two pre-treatments was only significant for the amendment SB80M20.

The control of the HS soil possessed a CA of $80^{\circ}$ and could be classified as hydrophilic (Figure 3), while the control of the soil from KD already exhibited a CA about $120^{\circ}$ and thus could be categorized as hydrophobic (Figure 4).

The application of the digestates to the HS soil increased the CA significantly $(p<0.05)$, except for the treatment ch-M100. The CA of the HS soil increased slightly more after the supply of digestates from ground IS compared with the CA amended with digestates derived from chopped IS. Only the amendment M100 exhibited a statistically significant difference between the two pre-treatments (Figure 3). After the supply of digestates to the KD soil, the CA of the amendments with exception of ch-SB100 went significantly beyond the untreated control $(p<0.05)$. The KD soil amended with the digestates of ground IS showed a lower wettability compared to the KD soil treated with chopped IS. The results showed a significant effect for the pre-treatment of the IS for M100 and SB100 (Figure 4).

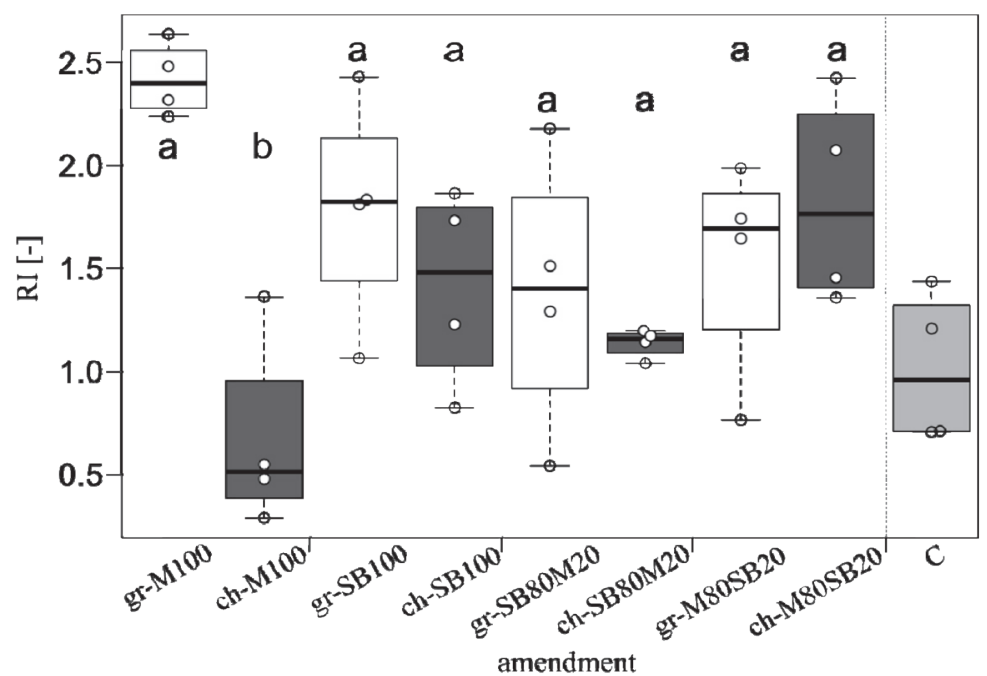

Figure 1. Repellency Index (RI) [-] of the loamy Cambic Luvisol (HS) amended with digestates derived from ground input substrate (IS) (white boxes) and from chopped IS (gray boxes) ( $\mathrm{n}=6)$ compared to the control (C). Different letters $(a b)$ indicate statistically significant differences $(P<0.05)$ of the pre-treatments. Boxes represent values within the $25^{\text {th }}$ to $75^{\text {th }}$ percentile; the whiskers indicate the range, and horizontal bars inside the boxes are the median values. 


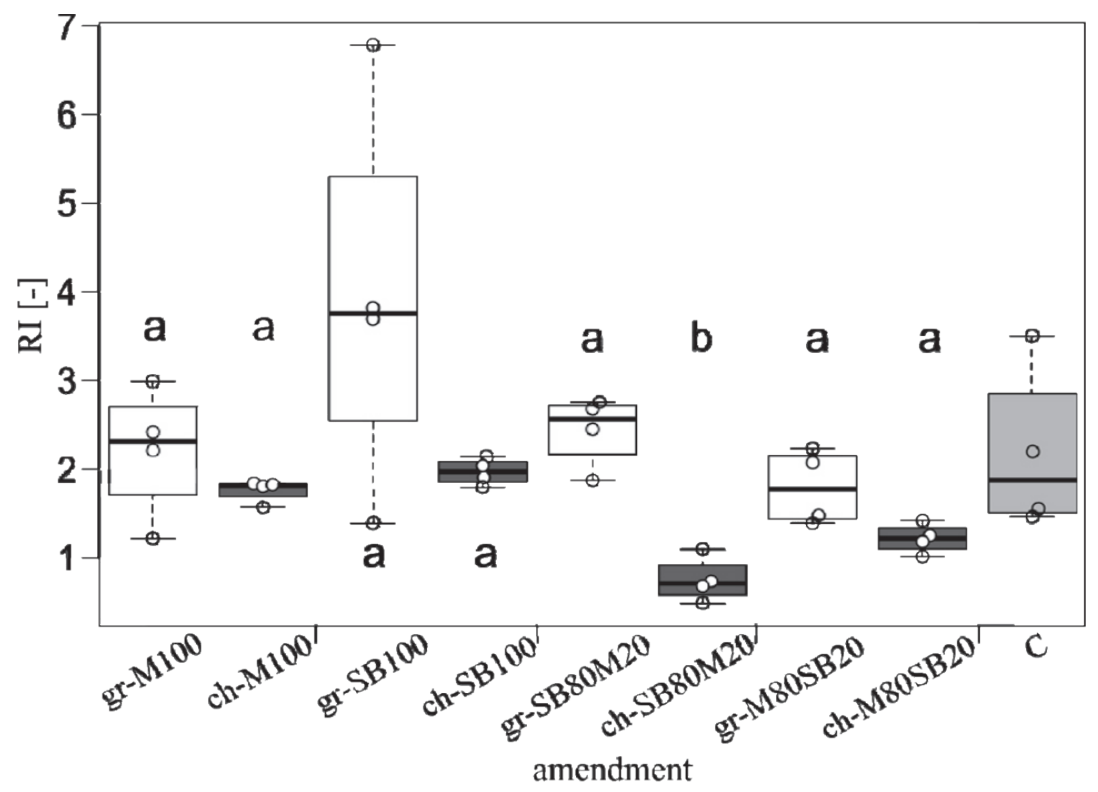

Figure 2. Repellency Index (RI) [-] of the sandy Podzol (KD) amended with digestates derived from ground input substrate (IS) (white boxes) and from chopped IS (gray boxes) $(\mathrm{n}=6)$ compared to the control (C). Different letters (ab) indicate statistically significant differences $(P<0.05)$ of the pre-treatments. Boxes represent values within the $25^{\text {th }}$ to $75^{\text {th }}$ percentile; the whiskers indicate the range, and horizontal bars inside the boxes are the median values.

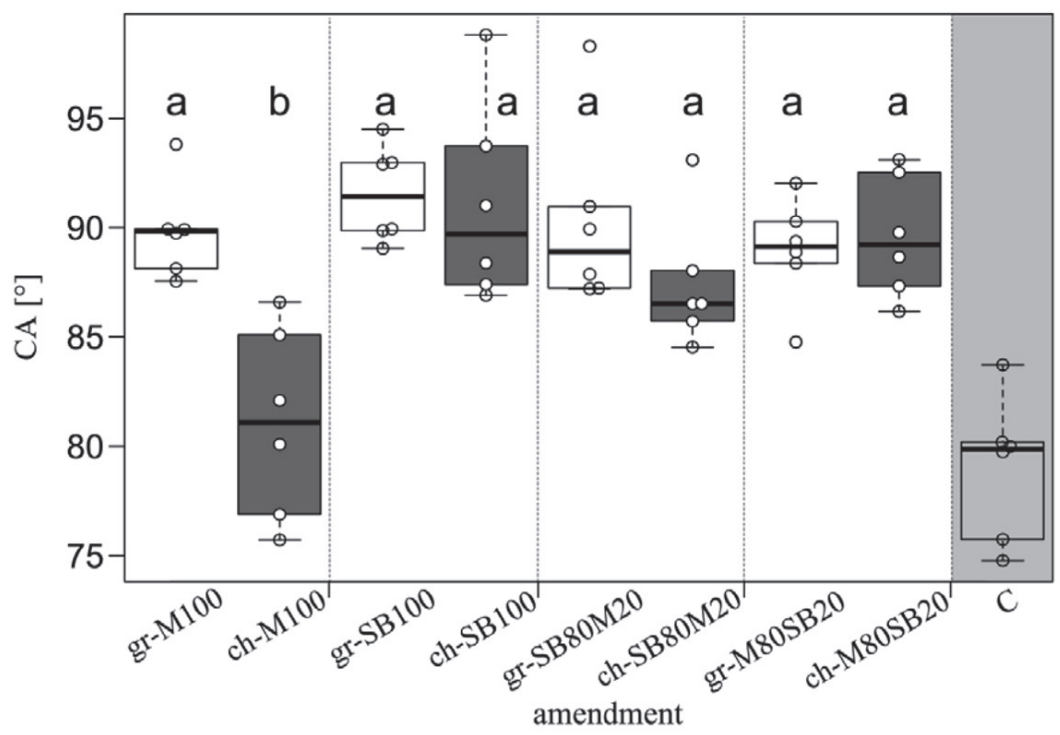

Figure 3. Contact angle (CA) $\left[^{\circ}\right]$ of the loamy Cambic Luvisol (HS) amended with digestates derived from ground input substrate (IS) (white boxes) and from chopped IS (gray boxes) $(n=6)$ compared to the control (C). Different letters $(\mathrm{ab})$ indicate statistically significant differences $(P<0.05)$ of the pre-treatments. Boxes represent values within the $25^{\text {th }}$ to $75^{\text {th }}$ percentile; the whiskers indicate the range, and horizontal bars inside the boxes are the median values. 


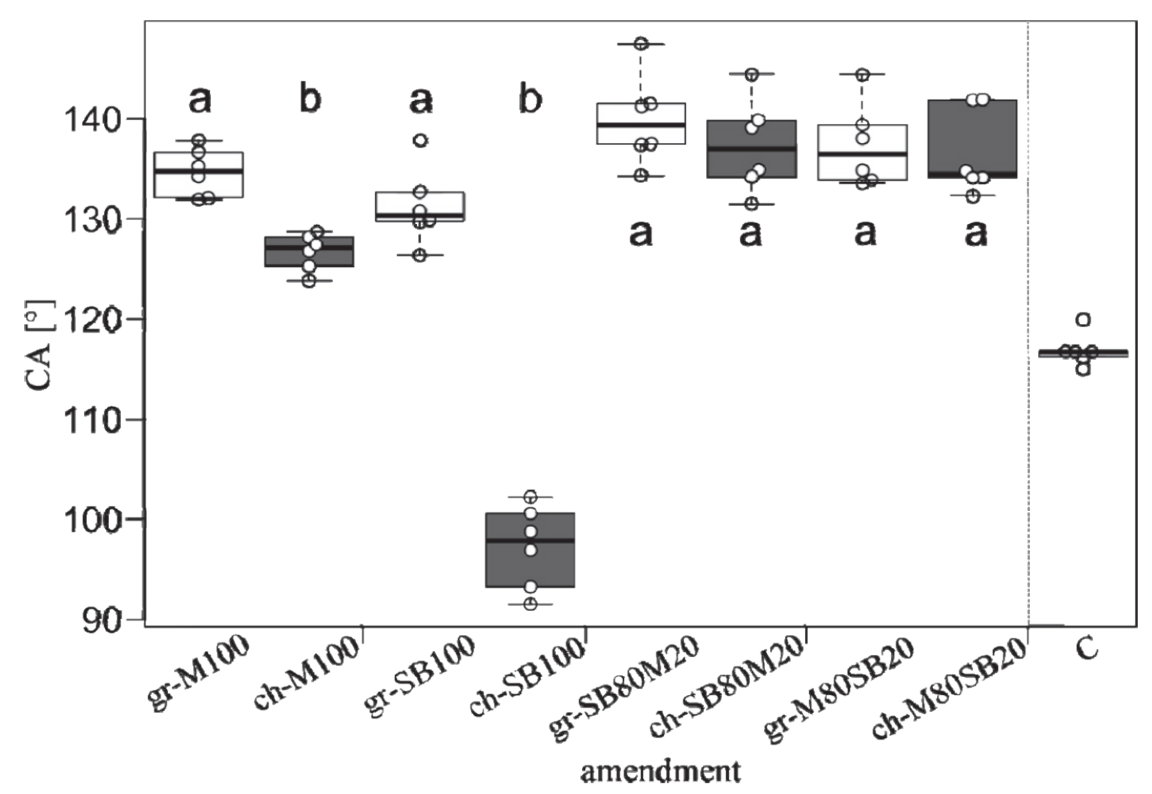

Figure 4. Contact angle $(\mathrm{CA})\left[^{\circ}\right]$ of the sandy Podzol (KD) amended with digestates derived from ground input substrate (IS) (white boxes) and from chopped IS (gray boxes) ( $\mathrm{n}=6)$ compared to the control $(\mathrm{C})$. Different letters $(\mathrm{ab})$ indicate statistically significant differences $(P<0.05)$ of the pretreatments. Boxes represent values within the $25^{\text {th }}$ to $75^{\text {th }}$ percentile; the whiskers indicate the range, and horizontal bars inside the boxes are the median values.

\section{Discussion}

\subsection{Effects of particle size reduction of the IS on physicochemical soil properties}

The effects of mechanical pre-treatment are attributed to the size reduction of the IS particles used for digestion and, thus, the enlargement of the specific surface area. The increasing specific surface area of the IS offers more unoccupied binding sites for various components. But also the enrichment of non-degradable substances occurs as a result of the enhanced biodegradability of easily available compounds in the ground IS.

The higher electrical conductivity of the A-horizon of the HS soil compared to the KD soil confirms that the loamy HS soil with its higher specific surface area offers a larger number of reactive binding sites for ions compared to the top soil layer of the sandy KD soil (Caravaca et al., 2001). The increasing EC in both soils after digestate application was due to an increased concentration of ions as a result of degradation of the organic matter during the fermentation process and the enrichment of inorganic compounds (Özyazici and Özyazici, 2012). Similar short-term increase of EC has been also observed after using comparable organic wastes, but they may cause serious limitations for seed germination and microbial activity as a side product after the addition of compost to the top layers of sandy and clayey oxisols (Bertoncini et al., 2008). However, the mechanical pre-treatment of the IS influences the amount of bound soluble salts, because, due to the reduction of the particle size of the IS, the surface area is increased (Ariunbaatar et al., 2014) 
reduction of the particle size of the IS, the surface area is increased (Ariunbaatar et al., 2014) which is confirmed by the results of the current study. Besides the particle size and surface area of the IS, the specific surface of the soil particles seems to be another factor defining the impact of digestates with different particles sizes. The ground IS particles are more decomposed, which results in an improved relocation of electrolytes, resulting in higher EC values in the HS soil. But this is not the case for the sandy KD soil, which might show the strong influence of soil texture. Due to the presence of larger pores, optimised infiltration processes may take place in the sandy KD soil. This result in a better displacement of larger particles derived from the chopped IS which, therefore, are translocated, or concentrated in smaller pores, or in the crotches of various pores. The possible higher dry matter content of the chopped IS compared to the ground IS provides clues about longer fibres of the chopped substrate, which can probably also lead to a higher fiber length in the digestates and which enables a better infiltration into the sandy compared to the loamy soil. The fiber length of the AD has to be investigated in further studies to draw conclusions regarding the infiltration behaviour of the digestates into differently textured soils.

\subsection{Effects of the chemical interactions between soils and $A D$ due to pre-treatment}

Alkalinisation of both soils after digestate application could be attributed to the alkaline character of the digestate itself due to high proportion of ammonium which is higher compared to the A-horizon of the soils. This was also found in the literature for agricultural wastes, compost, and digestates (e.g. Abdullahi et al., 2008). Besides the mechanical pre-treatment of the IS, the composition of the digestates (monofermentation/ cofermentation) seems to have had an impact on the $\mathrm{pH}$ value of the HS soil.
Alkalinisation of the soils after digestate application could be attributed to possible cofermentation effects, which could be the reason for different attributes of digestates from monofermentation and cofermentation on the $\mathrm{pH}$ of the loamy soil. It can be assumed that the loamy HS soil seems to be more sensitive to cofermentation effects compared to the sandy KD soil. Recent studies demonstrated that monofermentation of food wastes leds to more unstable conditions due to the accumulation of ammonia and volatile fatty acids (VFA's) during the fermentation process (Agyeman and Tao, 2014). This accumulation of VFA's causes a decrease in $\mathrm{pH}$ due to the imbalance of production and consumption of VFA during the anaerobic digestion of organic compounds such as carbohydrates and lipids (Ward et al. 2008) contained in the digestates. In contrast, co-digestion of cattle manure and food waste can enhance the anaerobic digestion process and can increase biogas production, and it avoids the enrichment of acidifying volatile acid compounds (Guo et al., 2014). This impact was also evident in higher contents of acetic acid equivalent contained in the digestates from monofermentation (M100), which indicates a less complete fermentation process compared to the digestates from cofermentation. However, higher concentrations of the different VFA's could be not detected in the used digestates with exception of the digestate M100, which contained a slightly higher amount of acetic acid compared to the other digestates. But the enhanced accessibility of the ground IS in combination with the high oxygen demand in the sandy KD soil may result in a soil $\mathrm{pH}$ decline due to an increased microbial degradation (Palmowski and Müller, 2000) and, thus, to a resultant nitrification.

An increased surface area due to the addition of ground material provides a better contact between the IS and the hydrolytic bacteria in the soil and consequently promotes the degradability of the organic substance in soils (Menardo et al., 2012). 


\subsection{Changing of soil wetting properties}

The effects of digestate amendment on soil wettability depend on soil moisture content, textural composition (Braun et al., 2010), and also the particle size of the IS used for digestion. Since air-dried soil is clearly hydrophobized by the digestates, the hydrophobisation of moist soil by the amendment can be observed. Organic compounds may infiltrate into the pore space acting as coatings surrounding soil particles. Under moist conditions, the hydrophobic group is repelled by water and adheres to the hydrophobic mineral particles (Nadav et al., 2013), while if the soil dries out and the water content of the soil falls beyond a critical water content (Badía et al., 2013), the amphiphilic molecules change their special orientation, putting the non-polar groups outwards and making the soil surface less wettable (Gonzáles-Peñaloza et al., 2013) (Figure 5). This is consistent with the increased CA values of the air-dried soils after digestate application. As a result of the insufficient drying of soils, the moist soil samples show a lower hydrophobicity (presented by the RI) compared to the air-dried soils.
However, besides the soil properties, the quality of the organic matter derived from the digestates is essential for the formation of hydrophobicity of the soil. The quality of the digestates is affected by the mechanical pre-treatment of the IS and, thus, the particle size because of the enrichment of non-biodegradable substances like recalcitrant long-chained fatty acids (e.g., humic and fulvic acids). The particle size and surface area were found to be the controlling factors determining the initial rates of hydrolysis (Eriksson et al., 2002), because the enhanced availability of the particles for microorganisms overwhelms the hydrolysis and acidogenesis step as well as the production of soluble organic compounds such as fatty acids during the anaerobic fermentation process (Komemoto et al., 2009). As a consequence, the excessive particle size reduction can led to an accumulation of fatty acids, which cannot be degraded by microorganisms (Hu et al., 2005). The result is an enrichment of nonbiodegradable substances (e.g., fatty acids) in the ground IS, which promotes the hydrophobisation and its perpetuation in soils.

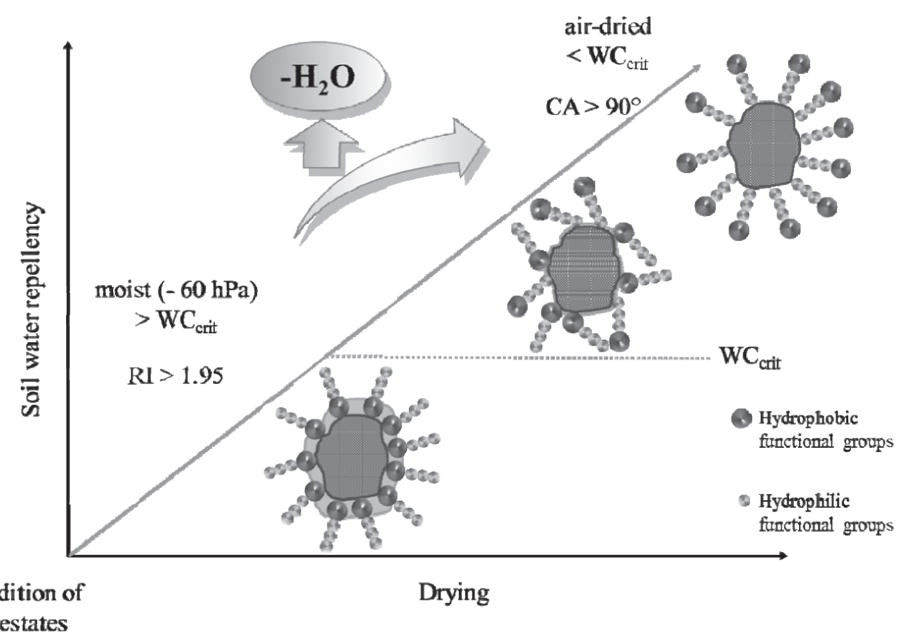

Figure 5. Schematic model of changes in water repellency after digestate application as a function of the critical water content (WCcrit) of soils. 


\section{Conclusion}

Mechanical pre-treatment (grinding/chopping) of input substrates for anaerobic digestion affects the impact of digestates on electrical conductivity, $\mathrm{pH}$, and wetting properties of soils. Our hypothesis has been confirmed partly from the results gained from this study. The application of digestates derived from ground IS resulted in a more reduced soil wettability compared to the wetting behavior after addition of digestates derived from chopped IS. This implies that anaerobic digestion from more finely ground IS produces a digestate with higher risk for soil degradation, because the result of hydrophobicity is reduced water infiltration into soils and hence a higher risk for soil erosion. A long-term consequence may be the loss of nutrients with the surface runoff and the subsequent reduction of soil fertility. The addition of the digestates derived from all input substrates to the soils results in both rising electrical conductivity and more alkaline conditions, and there is no clear evidence about the impact of mechanical pre-treatment for the effect of digestates on these properties. The soil texture has to be the decisive factor here to determine the effect of digestates from different pre-treatments. However, information on size of the particles and their surface area contained in the digestates after fermentation and their influence on soil properties is still scarce and has to be considered in further investigations.

It must also be noted that the inoculum itself may affect the soils. In a future study these aspects merit further considerations. It is important to note that, besides the mechanical pre-treatment of the IS for digestate production, there are other factors (e.g., drying and ensiling) that influence soil properties. These interactions have been neglected in this research and have to be conducted in further studies. It could, therefore, be concluded that the impact of differently prepared digestates on soil properties is still not completely understood. But the results gained in this study could serve as a first approach to clarify the effect of mechanical pre-treatment of IS on the impact of anaerobic digestates to soils. The findings can help to evaluate the economical costs for mechanical pre-treatment and its soil-related benefits.

\section{Acknowledgements}

The authors would like to thank the FNR (Fachagentur für nachwachsende Rohstoffe) for funding this study (FKZ 22401312). We acknowledge Ines Schütt and Doris Rexilius for their help with the laboratory measurements. We thank Prof. Dr. M.B. Kirkham, Kansas State University, USA, for improving the english text and for valuable remarks.

\section{References}

Abdullahi, Y.A., Akunna, J.C., White, N.A., Hallett, P.D.,Wheatley, R. 2008. Investigating the effects of anaerobic and aerobic post-treatment on quality and stability of organic fraction of municipal solid waste as soil amendment. Bioresour. Technol. 99, 8631-8636.

Agyeman, F.O., Tao, W. 2014. Anaerobic co-digestion of food waste and dairy manure: Effects of food waste particle size and organic loading rate. J. Environ. Manage. 133, 268-274.

Alburquerque, J. A., de la Fuente, C., Campoy, M., Carrasco, L., Nájera, I., Baixauli, C., Caravaca, F., Roldán, A., Cegarra, J., Bernal, M.P. 2012. Agricultural use of digestate for horticultural crop production and improvement of soil properties. Eur. J. Agron. 43, 119-128.

Antilén, M., Silva, K., Acevedo, S., Amiama, F., Faúndez, M., Knicker, H., Pizarro, C. 2014. Characterization of humic acids extracted from 
biosolid amended soils. J. Soil Sci. Plant Nutr. 14(4), 1005-1020.

Ariunbaatar, J., Panico, A., Esposito, G., Pirozzi, F., Lens, P.N.L. 2014. Pretreatment methods to enhance anaerobic digestion of organic solid waste. Appl. Energy. 123, 143-156.

Arye, G., Tarchitzky, J., Chen, Y. 2011. Treated wastewater effects on water repellency and soil hydraulic properties of soil aquifer treatment infiltration basins. J. Hydrol. 397, 136-145.

Bachmann, J., Arye, G., Deurer, M., Woche, S.K., Horton, R., Hartge, K.-H., Chen, Y. 2006. Universality of a surface tension-contact-angle relation for hydrophobic soils of different texture. J. Plant Nutr. Soil Sci. 169, 745-753.

Badía, D., Aguirre, J.A., Martí, C., Márquez, M.A. 2013. Sieving effect on the intensity and persistence of water repellency at different soil depth and soil types from NE-Spain. Catena. 108, 44-49.

Bertoncini, E.I., D’Orazio, V., Senesi, N., Mattiazzo, M.E. 2008. Effects of sewage sludge amendment on the properties of two Brazilian oxisols and their humic acids. Bioresour. Technol. 99, 4972-4979.

Braun, B., Böckelmann, U., Grohmann, E., Szewzyk, U. 2010. Bacterial soil communities affected by water-repellency. Geoderma. 158, 343-351.

Caravaca, F., Lax, A., Albaladejo, J. 2001. Soil aggregate stability and organic matter in clay and fine silt fractions in urban refuse-amended semiarid soils. Soil Sci. Soc. Am. J. 65, 12351238 .

Curaqueo, G., Meier, S., Khan, N., Cea, M., Navia, R. 2014. Use of biochar on two volcanic soils: effects on soil properties and barley yield. J. Soil Sci. Plant Nutr., 14(4), 911-924.

Eriksson, T., Borjesson, J., Tjerneld, F. 2002. Mechanisms of surfactant effect in enzymatic hydrolysis of lignocellulose. Enzyme Microb. Tech. 31, 353-364.

Gonzáles-Peñaloza, F.A., Zavala, L.M., Jordán, A., Bellinfante, N., Bárcenas-Moreno, G., MataixSolera, J., Granged, A.J.P., Granja-Martins, F.M., Neto-Paixão, H.M. 2013. Water repellency as conditioned by particle size and drying in hydrophobized sand. Geoderma. 209-210, 31-40.

Guo, J., Wang, W., Liu, X., Lian, S., Zheng, L. 2014. Effects of thermal pre-treatment on anaerobic codigestion of municipal biowastes at high organic loading rate. Chemosphere. 101, 66-70.

Hallett, P.D., Young, I.M. 1999. Changes to water repellence of soil aggregates caused by substrateinduced microbial activity. Eur. J. Soil Sci. 50, $35-40$.

Hu, Z.-H., Yu, H.-Q., Zhu, R.-F. 2005. Influence of particle size and $\mathrm{pH}$ on anaerobic degradation of cellulose by ruminal microbes. Int. Biodeter Biodegr. 55, 233-238.

Komemoto, K., Kim, Y.G.,Nagao, N., Onoue, Y., Niwa, C., Toda, T. 2009. Effect of temperature on VFA's and biogas production in anaerobic solubilization of wood waste. Waste Manage. 29, 2950-2955.

Lindmark, J., Leksell, N., Schnürer, A., Thorin, E. 2012. Effects of mechanical pre-treatment on the biogas yield from ley crop silage. Appl. Energy. 97, 498-502.

Magdoff, F., Weil, R.R. 2004. Soil organic matter management strategies. In: Magdoff, F., and Weil, R.R. 2004. Soil organic matter in sustainable agriculture. CRC Press, New York, 45-65.

Menardo, S., Airoldi, G., Balsari, P. 2012. The effect of particle size and thermal-pre-treatment on the methane yield of four agricultural by-products. Bioresour. Technol. 104, 708-714.

Nadav, I., Tarchitzky, J., Lowengart-Aycicegi, A., Chen, Y. 2013. Soil surface water repellency 
induced by treated wastewater irrigation: physicochemical characterization and quantification. Irrigation Sci. 31, 49-58.

Özyazici, M.A., Özyazici, G. 2012. Effects of sewage sludge on some basic productivity parameters of soil. Anadolu. J. Agr. Sci. 27, 101-109.

Palmowski, L.M., Müller, J.A. 2000. Influence of the size reduction of organic waste on their anaerobic digestion. Water Sci. Technol. 41, 155-162.

Réveillé, V., Mansuy, L., Jardé, É., Garnier-Sillam, É. 2003. Characterisation of sewage sludge-derived organic matter: lipids and humic acids. Org. Geochem. 34, 615-627.

Schlichting, E., Blume, H.-P., Stahr, K.. 1995. Bodenkundliches Praktikum: Eine Einführung in pedologisches Arbeiten für Ökologen, insbesondere Land- und Forstwirte und für Geowissenschaftler. 2nd, revised edition ed. Vol. 81. Berlin, Wien: Blackwell-Wissenschafts-Verlag.

Sciubba, L., Cavani, L., Marzadori, C., Ciavatta, C. 2012. Effect of biosolids from municipal sewage sludge composted with rice husk on soil functionality. Biol. Fertil. Soils. 49, 597-608.
Sørensen, P., Møller, H.B. 2009. Fate of nitrogen in pig and cattle slurries applied to the soil-crop system. In: Adani, F., Schievano, A., Boccasile, G. 2009. Anaerobic digestion: Opportunities for agriculture and environment. DiProVe University of Milan, Milan, 27-37.

Tejada, M., and González, J.L. 2007. Influence of organic amendments on soil structure and soil loss under simulated rain. Soil Tillage Res. 93, 197-205.

Tillman, R., Scotter, D., Wallis, M., Clothier, B. 1989. Water repellency and its measurement by using intrinsic sorptivity. Soil Res. 27, 637-644.

Wang, K., Yin, J., Shen, D., Li, N. 2014. Anaerobic digestion of food waste for volatile fatty acids (VFAs) production with different types of inoculum: Effect of pH. Biores. Technol. 161, 395-401.

Ward, A.J., Hobbs, P.J., Holliman, P.J., Jones, D.L. 2008. Optimisation of the anaerobic digestion of agricultural resources. Bioresour. Technol. 99, 7928-7940. 